\title{
SIMPLIFIED PROCEDURE FOR STRUCTURAL INTEGRITY EVALUATION OF COMPLEX WALLS THROUGH SIGNAL ENERGY ANALYSIS BASED ON VIBRATIONAL DATA
}

\author{
IVANO ALDREGHETTI, GIOSUÈ BOSCATO, MAURO FIORIN, \\ LORENZO MASSARIA \& VINCENZO SCAFURI \\ Laboratory of Strength of Material LabSCo, University Iuav of Venice, Italy
}

\begin{abstract}
The Structural Health Monitoring based on vibrational data offers an effective, reliable, and nondestructive methodology to assess the structural integrity of existing buildings. This aspect is particularly appreciated for the architectural heritage because enables to characterise the global structural condition of a monument in respect of its preservation. On the other hand, the structural assessment by dynamic identification is an onerous procedure, both in terms of costs of monitoring and data processing time. For this reason, the procedure proposed in this paper offers a simplified solution for structural integrity assessment. The goal is to detect, localise, classify, and assess the alteration of the global stiffness and weak areas through the comparison of the signal energy based on vibrational data and related pattern. The procedure was applied on a case study to better understand structural integrity procedure and to evaluate approach reliability. The time histories recorded on complex historical façade through "input-output" and "output only" methods were elaborated and compared. A fixed grid of excitation and recording points was created to map the distribution of signal energy values. The lower signal energy values are able to detect the loss of stiffness marking the vulnerability of structure, validated by experimental modal analysis. The comparison between experimental and numerical dynamic parameters with the results of signal energy analysis enables to identify the degree of connection between the sub-parts defining the potential macro-element mechanisms.
\end{abstract}

Keywords: SHM, signal energy, structural integrity, experimental modal analysis, dynamic identification.

\section{INTRODUCTION}

The conservation of cultural heritage depends on preventive control and monitoring of structures [1]-[4]. The methodology that guarantees the global control of structure aimed at verifying vulnerability is based on the analysis of vibrational response to ambient and mechanical actions. As the type of input varies, known or unknown, the EMA (Experimental Modal Analysis) and OMA (Operational Modal Analysis) are defined in input-output and only-output methodologies, respectively [5]-[9].

Although the reliability of the dynamic identification procedures is now proved [10][15], the methodology remains onerous in terms of time both in operational phase and in data processing phase. In this sense, this research proposes a simplified methodology based on vibrational analysis and relative signal energy to identify the critical areas that affect the global structural integrity.

Through a mapping of signal energy distribution of vibrational data building with respect to survey points and stressed areas, it is possible to identify the critical points. The procedure was applied to a case study through the excitation induced both by ambient noise and mechanically by means of the instrumented hammer.

In the first case, the structure was affected globally with an input that consistently involved the building; while in the second case the signal energy of locally induced vibration was suitably normalised with respect to the known input entity to compare the amplitudes of different signals. 
The results obtained were compared with the modal shapes identified experimentally, demonstrating the good reliability of proposed procedure.

\section{SIMPLIFIED PROCEDURE}

The disastrous events of the last decades that have affected the national and international cultural heritage have confirmed the need to monitor the structures to define a prevention approach for safeguarding.

The control/monitoring procedure enables a simple and immediate detection of crucial points that present discontinuity on structural integrity by analysing the vibration propagation on the structure. These points will be validated identifying modal shapes that reveal macroelements and/or sub-parts responses than global behaviour.

The proposed simplified procedure aims to interpret the values obtained from the analysis of the acceleration intensity of vibrations. The vibrations are induced mechanically by the impact hammer according to the input-output procedure. The method organises the signal energy values in a graduated scale from zero to the maximum value of the hammering, comparing the data collected in a given time lapse, the procedure characterizes the structure into coloured zones representing the value of signal energy.

The process to obtain this kind of graphics rendering in the procedure requires a vector file containing the drawing of the perimeter of the wall, the openings (see the left rectangle, Fig. 1) the positions of accelerometer sensors (circles 3, 5, 7,6 of Fig. 1) and hit points (filled circles B1 and B2 of Fig. 1), the vibrations and related signal energy values.

Then, the procedure will create a model where different channels are combined into adjacent triangles having three channels as vertices. It divides the sides of these triangles based on the signal energy dispersed on that distance (Fig. 2(a)) and then joins the points with the same value of the signal energy by means of a smooth curve (Fig. 2(b)).

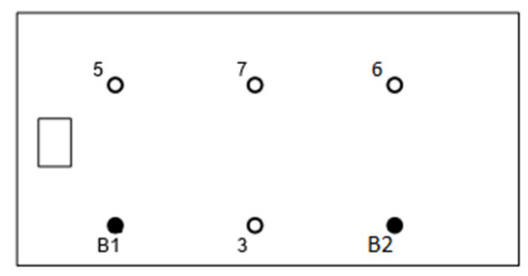

Figure 1: Generic façade: Data needed for the analysis with two hits (filled circles, B1 and B2) and channel points (circles 3, 5, 7, 6).

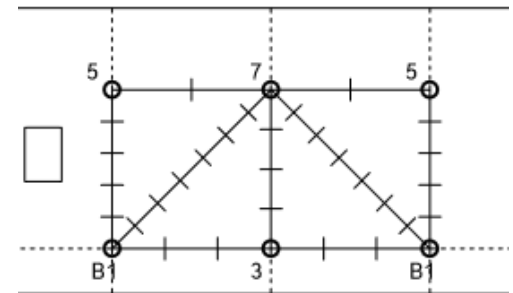

(a)

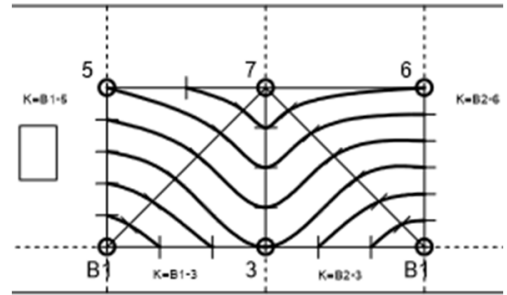

(b)

Figure 2: (a) Division by energy values of the initial scheme; and (b) Subsequent combination by means of a smooth curve. 
For the part of the façade that cannot be analysed with experimental data, the procedure applies a method where the signal energy for every point is based on:

$$
\mathbf{k}=\frac{\text { Hit's Energy }- \text { Point's Energy }}{\text { distance }}
$$

where $\boldsymbol{k}$ is the coefficient of energy dispersion on the façade and it depends on the position of the recording point compared to the hitting point and is calculated according to the closest signals (Fig. 3), and $d$ is the distance between the point and the reference hit point. In case of openings between the two points, the distance is calculated according to the minimum path between the recording point and hit point (Fig. 4).
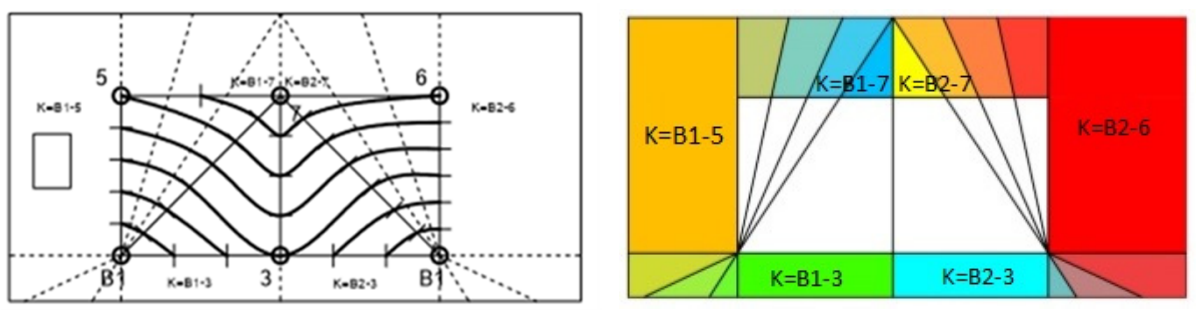

Figure 3: Division of the external part of the façade into areas with the same energy dispersion coefficient $\mathrm{k}$, and areas where $\mathrm{k}$ changes gradually in a radial manner with respect to the hit.

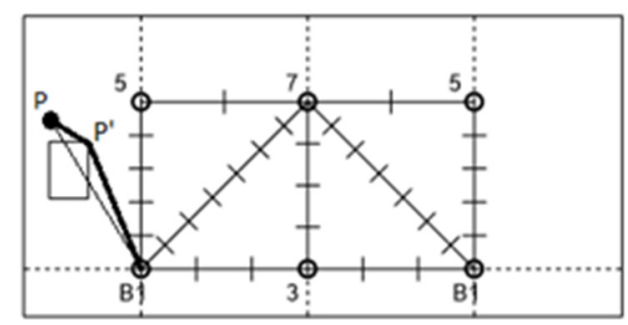

Figure 4: The distance between $\mathrm{P}$ and $\mathrm{B} 1$ is the sum of PP' and P'B1.

It is thus obtained the subdivision of façade that will be composed of uniform curved lines in the areas among measured channels, in circumference arcs on all constant dispersion coefficient zones that over the windows (Fig. 5).

An immediate understanding would be obtained by analysing the propagation of the vibration power by comparing each pixel calculated to the adjacent ones and reassigning a colour to their sum that highlights the energy absorbed by the façade. An energy value is assigned to each pixel, comparing this value with those of adjacent pixels, it is possible to assign the value of the dispersion coefficient (Fig. 6(a) and 6(b)). Using a colour scale for the values of $\boldsymbol{k}$, it is possible to obtain another graphic which highlights the different parts of the façade according to their response to the signal. In Fig. 6(c), red colour highlights the stiffest part of façade with a lower $\boldsymbol{k}$ value, whereas dark green colour characterises the most deformable part of the wall. 


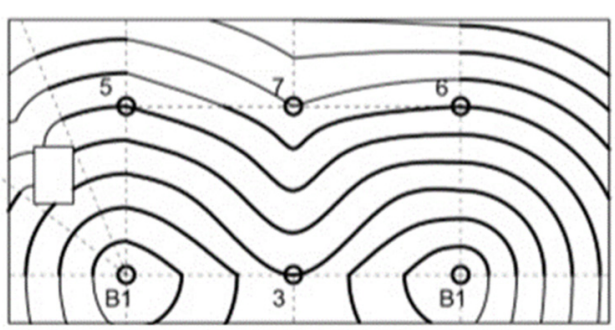

(a)

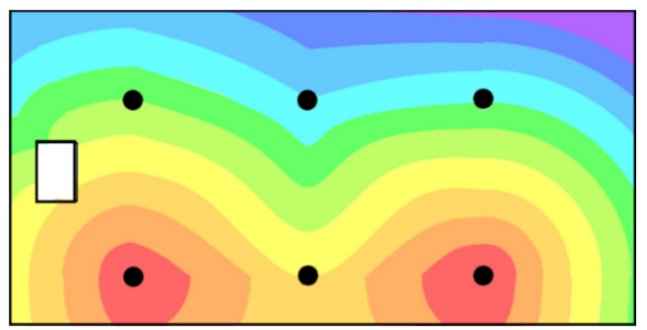

(b)

Figure 5: Contour plot and related colour map of unscaled signal energy over a generic façade.

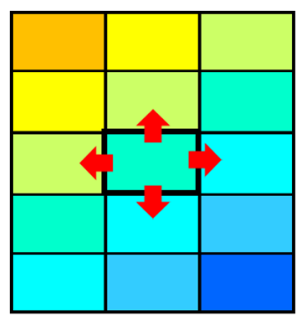

(a)

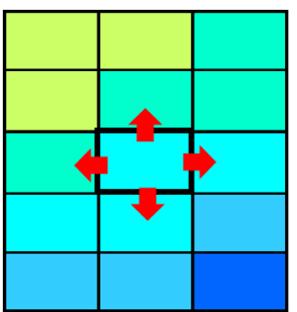

(b)

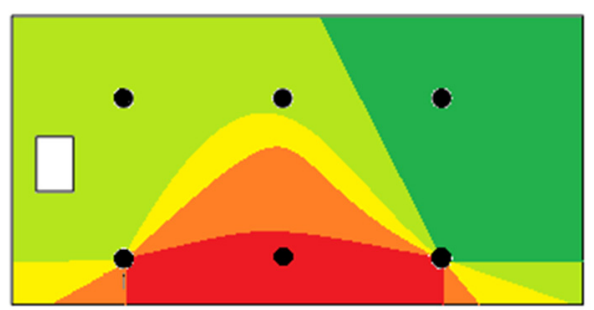

(c)

Figure 6: Pixel coloration in a deformable situation (a) or a rigid one (b) energy dispersion colour map over a generic façade (c).

Another type of analysis can be done with a different methodology, by comparing each pixel of Fig. 7(a), obtained using the vibration values measured in situ over the generic façade, with respect to the 'ideal' behaviour of the same façade (Fig. 7(b)). Fig. 8 shows the differences from the ideal model, expected in the case of a façade made of a homogeneous material and uniform thickness, characterised by an energy propagation equal to the average dispersion or that of standard masonry. The figure shows in shades of red in the areas with defective energy compared to the ideal situation and in blue those that are in excess. Fig. 9

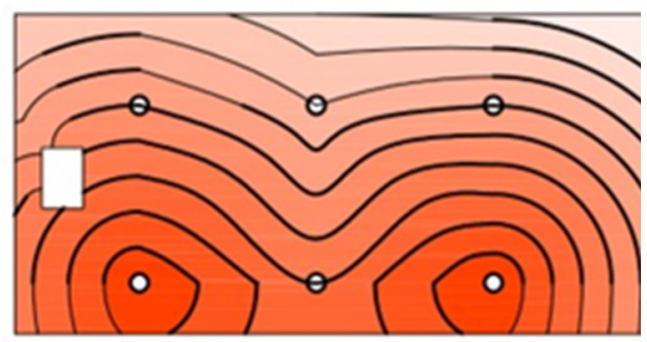

(a)

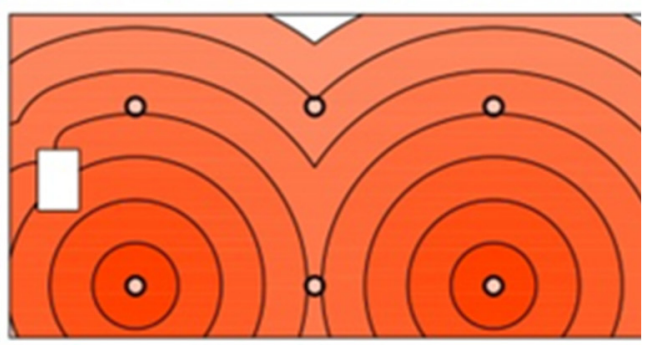

(b)

Figure 7: Vibration energy over a generic façade. (a) Real measured values; and (b) 'Ideal' values. 


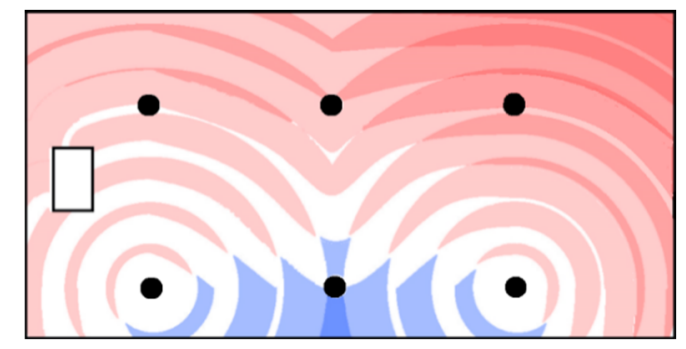

Figure 8: Difference between the real situation and ideal situation. In red the zones that are in defects and in blue the zones in excess of unscaled signal energy.

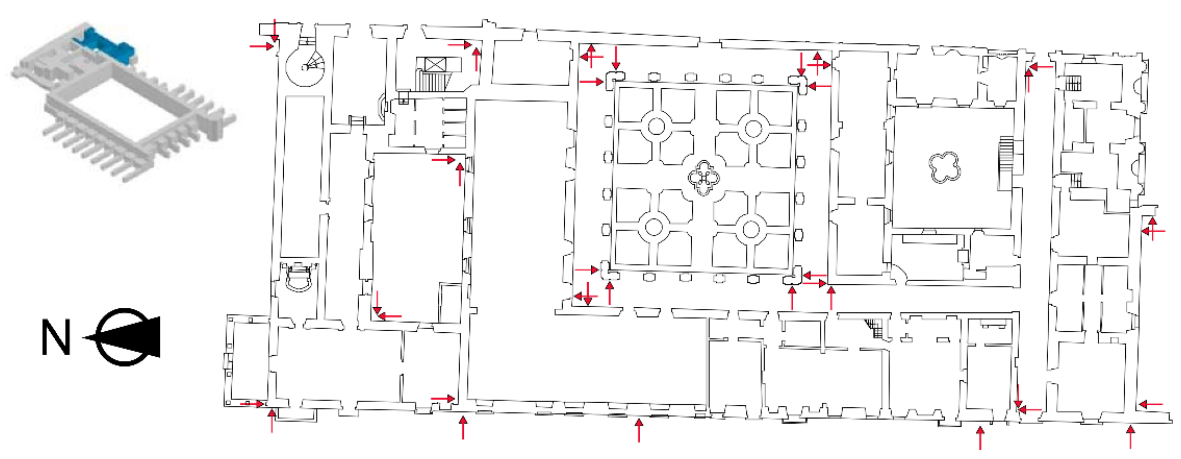

Figure 9: Scheme of the accelerometer directions, plan and 3D.

identifies areas having larger stiffness with blue colour and areas having an excessive deformability with a red colour.

\section{APPLICATION OF PROCEDURE TO CASE STUDY}

The proposed structural survey system is analysed through its application to a specific case study subject to monitoring.

The macro-volume Western Museum of Lucania and the House of the Priore of the Certosa di San Lorenzo in Padula (Salerno), Italy, see Fig. 9, were analysed, considering them as a structurally homogeneous area, since they both belong to the same period of construction. The sensor configuration for the dynamic monitoring was based on the planovolumetric composition of the structure. The vibration measurements were made using the accelerometer directions positioned according to the details in Fig. 9.

The modal shapes determined experimentally present large displacements corresponding to the macro-elements already identified through the planovolumetric characteristics of the building. The first mode of vibration (frequency $1.86 \mathrm{~Hz}$ and damping coefficient $1.51 \%$ ) shows that the most vulnerable part of the building is the western wall. This part is characterised by two internal floors and a basement, it has an irregular thickness along its height, and it is not characterised by orthogonal stiffening masonry walls, that causes the façade to be slender and vulnerable for the out-of-plane flexural mechanisms, Fig. 10.

The other vibration modes identified experimentally concern other sub-parts of the macro-volumes analysed. 


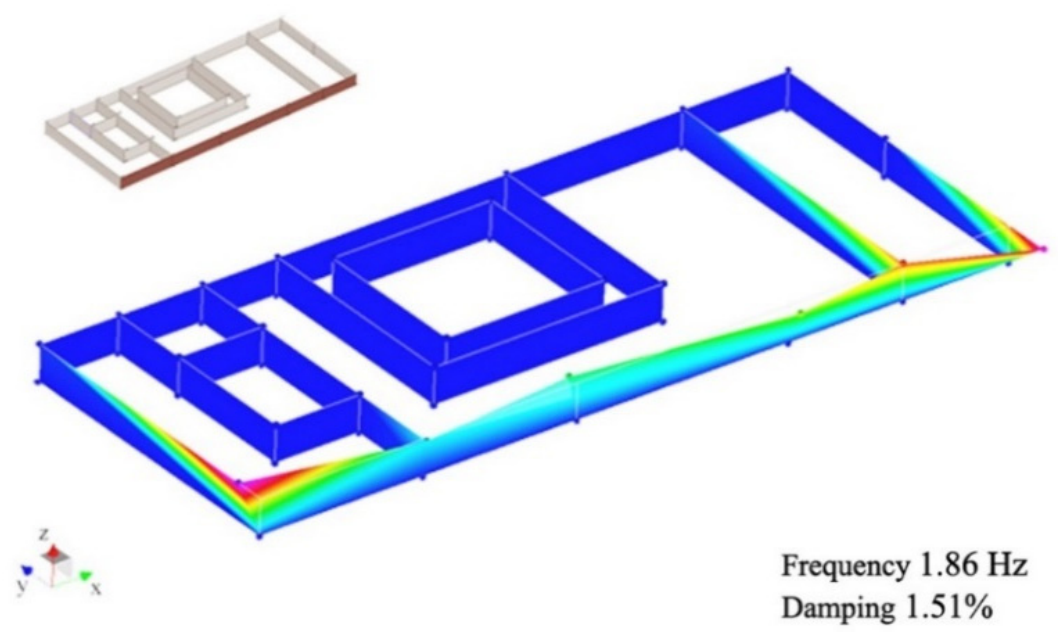

Figure 10: First modal shape of macro-volume that triggers the western wall response.

The western wall identified in the first modal shape of macro-volume (Fig. 9) is considered as a macro-element and it is analysed below (Fig. 11). The structural interaction between western wall and transversal wall was analysed by channels $\mathrm{CH} 2, \mathrm{CH} 6, \mathrm{CH} 12, \mathrm{CH} 4$, $\mathrm{CH} 9, \mathrm{CH} 3$ and $\mathrm{CH} 7$ (see Fig. 11, red box).

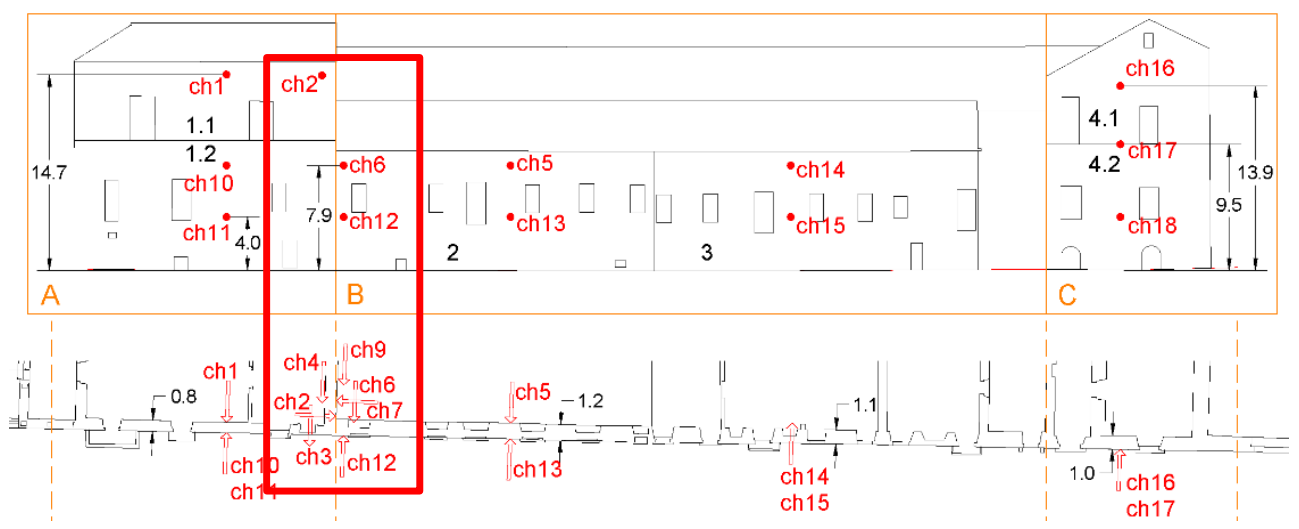

Figure 11: Front and related plan with sensors scheme of western wall.

4 DYNAMIC IDENTIFICATION INPUT/OUTPUT AND OUTPUT ONLY

Fig. 12 shows the sensors, the hit position and the model used for the dynamic identification of the western wall.

The 16 channels registered both the vibration induced by environmental noise and the one generated through the impact hammer from 10 hits (Fig. 12, blue rows). It is necessary to point out that for hit 5 it was necessary to eliminate the signal recorded by channel 15 , since the signal saturated because of excessive proximity to hit point. 

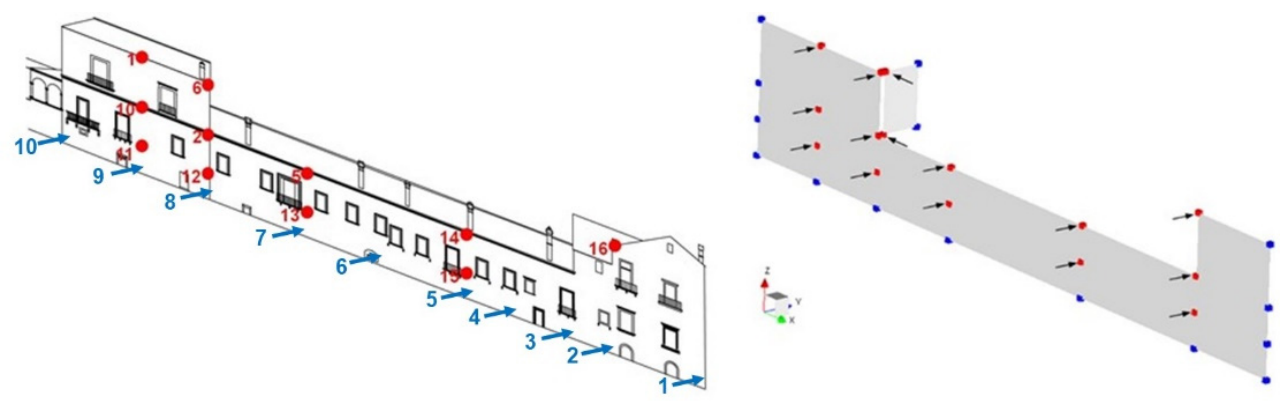

Figure 12: D scheme of accelerometer position, direction (red circles) and hit points (blue rows).

The values obtained were normalised in function of different entities of hits and then processed to calculate the signal energy at each excitation. The data obtained from the channels were sorted according to each analysed wall panel (see Fig. 11) and coloured based on a representative scale for an immediate visual interpretation, Tables 1 and 2.

Table 1: Hit input, signal energy values (gravitational acceleration, g).

\begin{tabular}{|c|c|c|c|c|c|c|c|c|c|c|c|c|c|c|c|}
\hline & \multicolumn{15}{|c|}{ Accelerometer positions } \\
\hline & \multicolumn{6}{|c|}{ ME1 } & \multicolumn{2}{|c|}{ ME2 } & \multicolumn{2}{|c|}{ ME3 } & \multirow{2}{*}{\begin{tabular}{c|} 
ME4 \\
16 \\
\end{tabular}} & \multicolumn{4}{|c|}{$\begin{array}{c}\text { Connection between } \\
\text { western wall and transversal } \\
\text { wall }\end{array}$} \\
\hline & 1 & 10 & 11 & 2 & 6 & 12 & 5 & 13 & 14 & 15 & & 3 & 7 & 4 & 9 \\
\hline Hit 1 & 0.0022 & 0.0004 & 0.0004 & 0.0019 & 0.0003 & 0.0007 & 0.0004 & 0.0008 & 0.0006 & 0.0008 & 0.0392 & 0.0006 & 0.0002 & 0.0003 & 0.0003 \\
\hline Hit 2 & 0.0022 & 0.0007 & 0.0004 & 0.0021 & 0.0004 & 0.0008 & 0.0006 & 0.0025 & 0.0014 & 0.0022 & 0.1119 & 0.0009 & 0.0004 & 0.0004 & 0.0004 \\
\hline Hit 3 & 0.0022 & 0.0036 & 0.0009 & 0.0019 & 0.0004 & 0.0007 & 0.0007 & 0.0010 & 0.0026 & 0.0018 & 0.0174 & 0.0009 & 0.0008 & 0.0004 & 0.0003 \\
\hline Hit 4 & 0.0022 & 0.0021 & 0.0004 & 0.0020 & 0.0009 & 0.0009 & 0.0019 & 0.0021 & 0.0226 & 0.0087 & 0.0212 & 0.0017 & 0.0009 & 0.0006 & 0.0004 \\
\hline Hit 5 & 0.0025 & 0.0011 & 0.0003 & 0.0022 & 0.0038 & 0.0011 & 0.0138 & 0.0075 & 0.2379 & 8.6534 & 0.0034 & 0.0023 & 0.0028 & 0.0008 & 0.0008 \\
\hline Hit 6 & 0.00 & 0.001 & 0.000 & 0.0032 & 0.0073 & 0.0023 & 0.0497 & 0.0319 & 0.0399 & 0.0 & 0.0033 & 0.0047 & & 60.00 & 0.0017 \\
\hline Hit 7 & 0.0052 & 0.0032 & 0.0009 & 0.0059 & 0.0432 & 0.0081 & 0.3310 & 1.5385 & 0.0261 & 0.0062 & 0.0021 & 0.0076 & 0.0172 & 0.0037 & 0.0082 \\
\hline Hit 8 & 0.0034 & 0.002 & 0.0021 & 0.0052 & 0.0407 & 0.0486 & 0.0148 & 0.0079 & 0.0073 & 0.0013 & 0.0014 & 0.0035 & 0.0076 & 0.0033 & 0.0041 \\
\hline Hit 9 & 0.0069 & 0.0283 & 2.0861 & 0.0073 & 0.0150 & 0.0078 & 0.0034 & 0.0042 & 0.0013 & 0.0008 & 0.0009 & 0.0054 & 0.0114 & 0.0048 & 0.0045 \\
\hline Hit 10 & 0.0032 & 0.0013 & 0.0017 & 0.0019 & 0.0006 & 0.0007 & 0.0002 & 0.0012 & 0.0002 & 0.0005 & 0.0012 & 0.0015 & 0.0011 & 0.0008 & 0.0003 \\
\hline $\begin{array}{l}\text { Mean } \\
\text { value }\end{array}$ & 0 & 0.00 & 35 & 34 & 0.0019 & 0.0019 & 0.0045 & 0.0034 & 0.0057 & 0.0019 & 0.0056 & 0.0029 & 0.0047 & $7 \mid 0.0017$ & 0.0021 \\
\hline SD \% & 0.1 & 0.11 & 0.06 & \begin{tabular}{|l|l|}
0.16 \\
\end{tabular} & 0.27 & 0.25 & 0.62 & 0.29 & 0.93 & 0.33 & \begin{tabular}{|l|l|}
0.73 \\
\end{tabular} & 0.23 & 0.57 & $\begin{array}{ll}0.17 \\
\end{array}$ & 0.27 \\
\hline
\end{tabular}

Table 2: Ambient vibration input, signal energy values (gravitational acceleration, g).

\begin{tabular}{|l|c|c|c|c|c|c|c|c|c|c|c|c|c|c|c|}
\hline & \multicolumn{10}{|c|}{ Accelerometer positions } \\
\cline { 2 - 15 } & \multicolumn{9}{|c|}{ ME1 } & \multicolumn{10}{|c|}{ ME2 } & \multicolumn{2}{c|}{ ME3 } & ME4 & $\begin{array}{c}\text { Connection between } \\
\text { western wall and } \\
\text { transversal wall }\end{array}$ \\
\cline { 2 - 15 } & 1 & 10 & 11 & 2 & 6 & 12 & 5 & 13 & 14 & 15 & 16 & 3 & 7 & 4 & 9 \\
\hline $\begin{array}{l}\text { Signal } \\
\text { energy }\end{array}$ & 0.201 & 0.039 & 0.037 & 0.168 & 0.072 & 0.055 & 0.060 & 0.094 & 0.027 & 0.066 & 0.215 & 0.058 & 0.026 & 0.026 & 0.036 \\
\hline
\end{tabular}


Tables 1 and 2 show the energy values (expressed in gravitational acceleration, g) for each channel based on different input, represented by the hits with the instrumented hammer and ambient vibration. The red values show overflow data. Four macro-elements are identified by ME1, ME2, ME3 and ME4 (see Fig. 11); while the last four columns refer to connection between western wall and transversal wall (see Fig. 11). In the last two rows of Table 1 are listed the mean value and the standard deviation (SD).

Table 2 shows the energy values of recorded signal induced by ambient vibrations.

Table 1 allows to immediately note the criticality of channel 11, followed by channels 10 , 6, 12 and 5. These channels are placed in areas of the wall that can be considered less stiff, since the signal energy is exhausted quickly before being detected. These channels therefore consist mainly of low values except for the presence of extremely high sudden peaks detected in the case in which the hit is close to recording channel.

As well known, a façade portion simply subjected to ambient vibration is characterised by larger signal energy values in stiff areas and smaller energy values in deformable areas.

In Fig. 13 channels 10 and 11 are in points characterised by structural discontinuity that does not transmit efficiently the accumulated accelerations unlike channels 1 and 2 which are located in the stiffest points of the wall.

The same approach was adopted with vibration induced by impact hammer. For this analysis, along each column of channels, the values obtained when the hit gets too close to the channels had to be removed because they can invalidate the average recorded value. Hit number 9 is eliminated from channels 1, 10 and 11; Hits 7 and 8 from channels 6 and 12 (channel 2 is considered sufficiently distanced thanks to the irregularity in elevation of the façade from Zone A to Zone B, see Fig. 11); Hits 6 and 7 from the channels 5 and 13; Hits 4, 5 and 6 from the channels 14 and 15; Hits 1, 2 and 3 from channel 16. Even in this case, if represented graphically as in Fig. 13, it is evident that channels 6, 10,11 and 12 are in areas characterised by structural discontinuity, differently than channels 1 and 2 . In this type of analysis, it can be noted that wall stiffness close to channel 15 seems to be smaller than that determined close to channel 14. This result confirms the analysis of recorded signals from ambient vibrations.

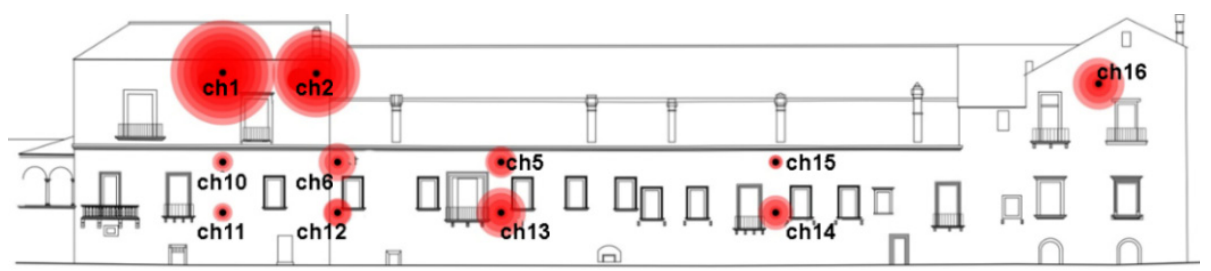

Figure 13: Scheme of signal energy values in case of ambient vibration.

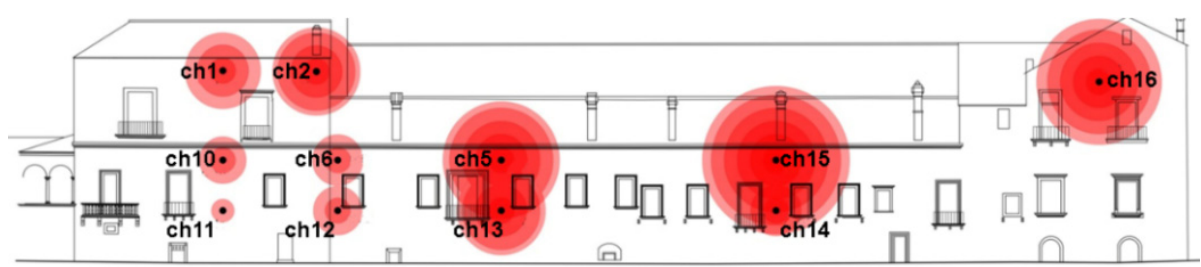

Figure 14: Scheme of signal energy values in case of vibration induced by hits. 
Figs 15 and 16 shows the map of signal energy over the entire western wall and highlights the problem of vibration transfer over the façade. This image was obtained by adding together the signal energy values measured for each channel for hits 10, 8, 6, 4 and 3. Dividing the signal energy values in different colour zones can represent the ability to dissipate or accumulate the acceleration of the induced vibrations.

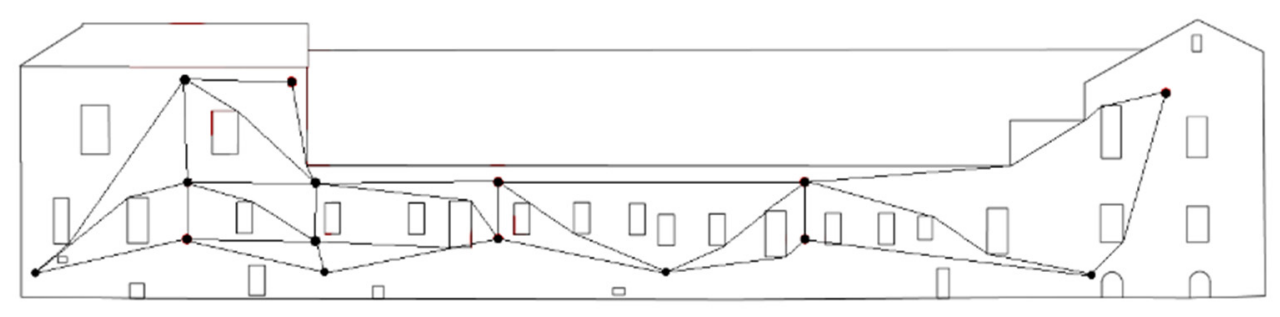

Figure 15: Outline of the distances between channels and hits on the façade.

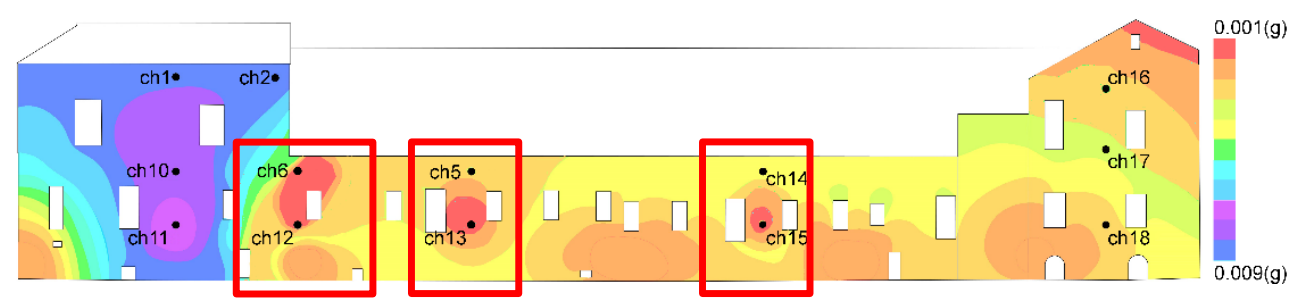

Figure 16: Coloured graphic scheme of the façade behaviour with hits 10, 8, 6, 4 and 3.

The distance between one channel and the second one is highlighted by a segment (Fig. 15), which is divided in proportion to the energy values of the channels and adopting a coloured reference scale. A contour map is then generated, with contour lines perpendicular to the points along the segments connecting adjacent channels and by dividing. the façade in areas having the same energy range, obtaining an approximated pattern of the signal energy.

Reading this result, it is necessary to pay attention to variations in the signal energy values between the points, that is, when two points close to each other have a significant difference in the value of the signal energy. An example is the area close to point 12, where great dispersion of energy can be observed. The same chromatic difference is found for example from channel 16 to hit 3 in more than $13 \mathrm{~m}$. The same trend can be seen in channel 15 compared to channel 14, where one is probably influenced by the presence of a flue and the other one is stiffened by the presence of the roof (Fig. 12).

Comparing the results of Figs 14 and 15 it is clear that the vulnerability zones of the façade are localised close to points 11,12,13,15 and 16.

What is interpreted through the analysis of the signal energy is confirmed by the experimentally identified modal shapes, showed in Fig. 17. It is evident from the triggered modes that the most vulnerable zones mainly concern points 11, 12, 13, 15 and 16 (Figs 11, 12 and 18). 


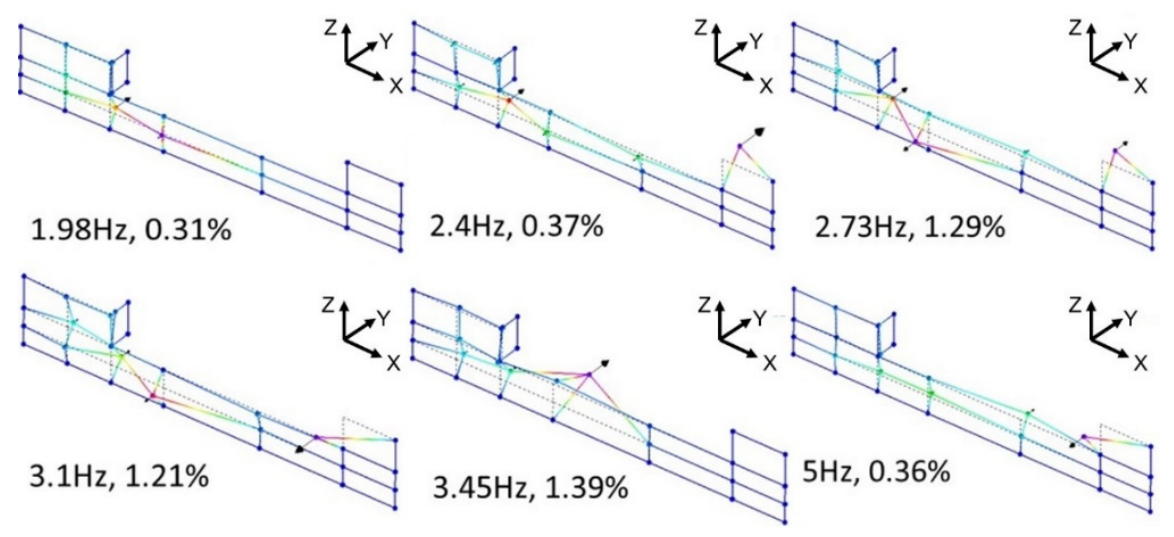

Figure 17: Dynamic identification of West wall.

Fig. 18 schematises the main experimental modal shapes that trigger the flexural horizontal and vertical mechanisms of macro-elements M1-M2 and M4 respectively. The displacements entities are not significant then were omitted. Out-of-plane vertical mechanism that involves ME4 is well known, while the combined mechanism that involves ME1 and ME2 is investigated in Section 5. This potential mechanism was identified by the proposed procedure and confirmed by experimental dynamic identification (see Fig. 19).
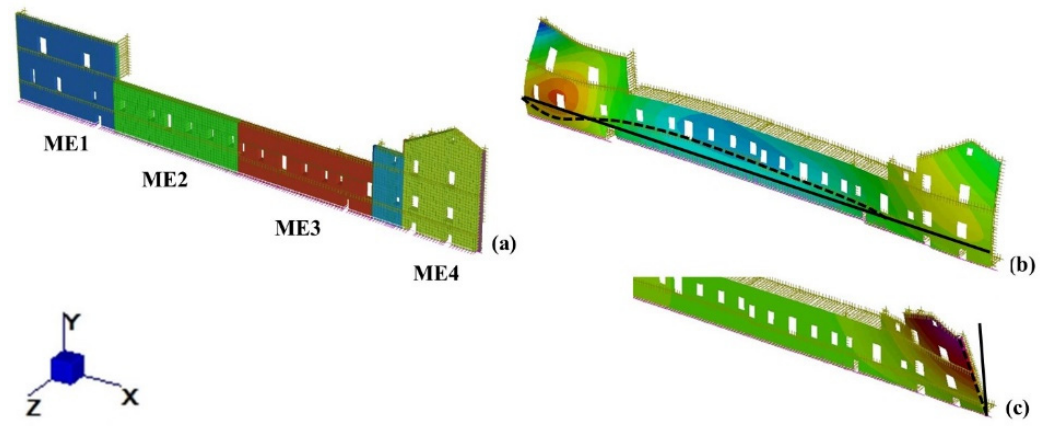

Figure 18: Macro-elements and potential mechanisms. (a) Macro-elements; (b) Out-ofplane horizontal mechanism of ME4; and (c) Out-of-plane vertical mechanism of ME1-ME2.

\section{LOCAL MECHANISM}

The macro-elements vulnerability can be evaluated through the analysis of the dynamic behaviour of structure correlating the modal shapes to local mechanisms.

The case study highlighted some local mechanisms, which involve both parts of macrovolumes triggered by the irregularity in elevation. The local mechanism was triggered by vertical bending of wall; nevertheless, the structural interaction between walls is affected by: (i) the degradation of structural interaction among west wall and normal walls; (ii) the irregularity along wall elevation; and (iii) the geometric slenderness of wall. 
The modal shapes show the structural interaction between West-wall and perpendicular wall between ME1 and ME2 (see Fig. 19), in particular no interaction is found up to $4 \mathrm{~m}$. Despite the irregularity along wall height, the effect of the roof guarantees structural continuity between walls. At a height of $8 \mathrm{~m}$, the modal deformations coincide for both modes, confirming a good structural interaction between walls conferred by the corner connection. Fig. 19 shows the wall mechanism that enables to analyse the structural interaction between adjacent buildings, connected or in adherence, which constitutes the complex and/or aggregate system.

Despite the well-known out-of-plane mechanism, the one analysed is instead characterised by the upper stiff plane or volume which triggers an overturning mechanism generated by stiff overlapping volumes. Furthermore, the presence of effectively connected horizontal floor and corners with an effective degree of constraint, and the lack of connection with the orthogonal walls influence the potential mechanism (Fig. 19(a)), especially for a slender wall such as the west wall.

The second mode identified (Fig. 19(b)) can be defined as an out-of-plane mechanism triggered by the loss of interaction with the transverse wall; the hammering effect of the perpendicular wall and the loss of effectiveness of the interaction contribute to the overturning mechanism of the macro-element (Fig. 19(c)).

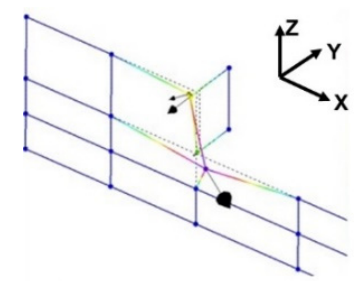

Mode1 $2.6 \mathrm{~Hz}, 2.95 \%$

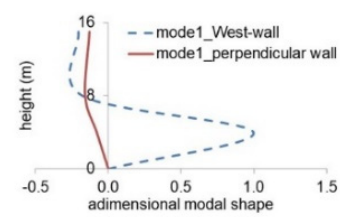

(a)

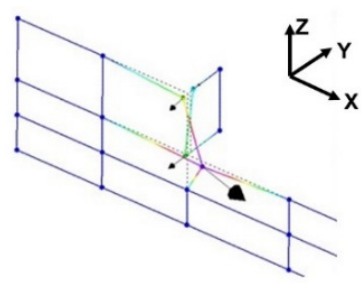

Mode2 $3.02 \mathrm{~Hz}, 1.97 \%$

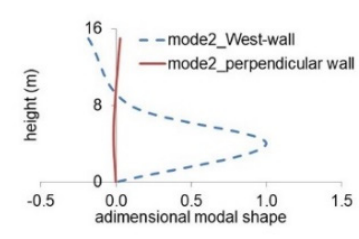

(b)

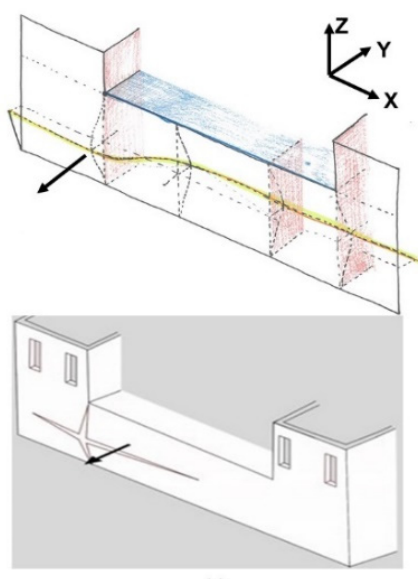

(c)

Figure 19: Main modal shape of west wall, potential failure local mechanism of wall.

\section{CONCLUSIONS}

The proposed procedure enables to evaluate the structural integrity through acceleration measurements induced by mechanical and/or ambient vibrations. The simplified procedure enables to identify the critical points of façade defining the potential failure mechanisms.

The recorded signal energy values are mapped through a graduated scale from 0 to the maximum value normalised by greater hit values to design the graphic model.

The procedure steps are:

- knowing in advance the geometric measurements of the wall fixing the recording points and return them in vector format;

- $\quad$ recording the vibrations on the wall assuring an acceptable noise-signal relationship; 
- $\quad$ filtering and cutting the significative recorded signal;

- the tests should be carried out by combined procedure, input-output and output-only; and

- the data should be processed to calculate the normalised energy signal as a function of the input.

In this phase the procedure is reliable in case of façades represented as two-dimensional macro-elements; further developments are needed to evaluate other applications to more complex three-dimensional mechanisms.

\section{REFERENCES}

[1] Farrar, C.R. \& Worden, K., An introduction to structural health monitoring. Philosophical Transactions of the Royal Society A, 365(1851), pp. 303-315, 2007.

[2] Syrmakezis, C.A., Seismic protection of historical structures and monuments. Structural Control and Health Monitoring, 13, pp. 958-979, 2006.

DOI: $10.1002 /$ stc.89.

[3] De Stefano, A. \& Ceravolo, R., Assessing the health state of ancient structures: The role of vibrational tests. Journal of Intelligent Material Systems and Structures, 18, pp. 793-807, 2007.

[4] D’Ambrisi, A., Mariani, V. \& Mezzi, M., Seismic assessment of a historical tower with advanced numerical model tuned on ambient vibration data. Advanced Material Research, 133-134, pp. 617-622, 2010.

[5] Ceravolo, R., Pistone, G., Zanotti Fragonara, L., Massetto, S. \& Abbiati, G., Vibrationbased monitoring and diagnosis of cultural heritage: A methodological discussion by way of three examples. International Journal of Architectural Heritage, 2014.

DOI: $10.1080 / 15583058.2013 .850554$.

[6] Podestà, S., Riotto, G. \& Marazzi, F., Reliability of dynamic identification techniques connected to structural monitoring of monumental buildings. Structural Control and Health Monitoring, 15, pp. 622-641, 2008. DOI: 10.1002/stc.219.

[7] Sepe, V., Speranza, E. \& Viskovic, A., A method for large-scale vulnerability assessment of historic towers. Structural Control and Health Monitoring, 15, pp. 389415, 2008. DOI: 10.1002/STC.24.

[8] Ceroni, F., Sica, S., Garofano, A. \& Pecce, M., SSI on the dynamic behaviour of a historical masonry building: Experimental versus numerical results. Buildings, 4, pp. 978-1000, 2014.

[9] Diaferio, M., Foti, D., Giannoccaro, N.I. \& Ivorra, S., Optimal model through identified frequencies of a masonry building structure with wooden floors. International Journal of Mechanical, 8, pp. 282-288, 2014.

[10] Gallipoli, M.R. et al., Empirical estimates of dynamic parameters on a large set of European buildings. Bulletin of Earthquake Engineering, 8, pp. 593-607, 2010.

[11] Ramos, L.F., Alaboz, M. \& Aguilar, R., Dynamic identification and monitoring of St. Torcato Church. Advanced Material Research, 133-134, pp. 275-280, 2010.

[12] Ramos, L.F., Marques, L., Lourenço, P.B., De Roeck, G., Campos-Costa, A. \& Roque, J., Monitoring historical masonry structures with operational modal analysis: Two case studies. Mechanical Systems and Signal Processing, 24, pp. 1291-1305, 2010.

[13] Gentile, C. \& Saisi, A., Ambient vibration testing of historic masonry towers for structural identification and damage assessment. Construction and Building Materials, 21, pp. 1311-1321, 2007. 
[14] Foti, D., Diaferio, M., Mongelli, M., Giannoccaro, N.I. \& Andersen, P., Operational modal analysis of an historical tower in Bari. Conference Proceedings of the Society for Experimental Mechanics Series, IMAC XXIX, vol. 7, Jacksonville, pp. 335-342. DOI: 10.1007/978-1-4419-9316-831.

[15] Aras, F., Krstevska, L., Altay, G. \& Tashkov, L., Experimental and numerical modal analyses of a historical masonry palace. Construction and Building Materials, 25, pp. 81-91, 2011. 